\title{
ALGUNS DADOS SOBRE A REPRODUÇÃO DO GARIBÁLDI, AGELAIUS R. RUFICAPILLUS (ICTERIDAE, AVES) EM LAVOURAS DE ARROZ NO RIO GRANDE DO SUL
}

Maria Alice Bello Fallavena

\begin{abstract}
Agelaius r. ruficapillus is gregarious, being found in large flocks in Rio Grande do Sul during most of the year; they nest in natural marshes or rice fields. This bird is accused by farmers of causing damage to rice at all stages of its growth and Belton, 1985, believes it may now be the most abundant bird in the state.

Its reproductive biology in rice fields in southern Rio Grande do Sul was observed from 1981 to 1983, with more emphasis from november 1982 to march 1983. Capture and banding of 16 birds with aluminum and plastic colored bands were made; nine nests were marked with steel stakes. It was found that the male is responsible for the construction of the nest, which the female lines inside. The clutch varies from three to four eggs, three being more frequent. The female broods the eggs and leaves the nest to feed. The male stays near the nest, defending the territory. The young hatch after 13 days of brooding, and are fed arthropods by the parents. After fledging they receive grains of dehulled rice. Reproduction is synchronized with rice growth. It begins with flowering and ends at harvest time. Adult birds feed on rice during the entire growth period, taking the "milk" of green rice and eating ripe grains after dehulling them.
\end{abstract}

\section{INTRODUÇÃO}

O gênero Agelaius é constituído por nove espécies (Howard \& Moore, 1980); destas, sete se reproduzem em zonas de banhados (Post, 1981). Cinco são espécies sul-americanas e apenas duas destas tiveram sua biologia estudada até o momento: A. icterocephalus (Wiley \& Wiley, 1980) e A. thilius (Orians, 1980). As outras três espécies são muito pouco conhecidas.

A. ruficapillus apresenta duas subespécies: $A$. r. ruficapillus e $A$. $r$.

1. Museu de Ciências Naturais da Fundação Zoobotânica do Rio Grande do Sul. Bolsista do Conselho Nacional de Desenvolvimento Científico e Tecnológico (CNPq). 
frontalis. Segundo Pinto, 1944 e Paynter, 1968 a subespécie tipo é a que ocorre no Rio Grande do Sul, tendo estes autores feito seus registros somente para o oeste e sudoeste do Estado, respectivamente. Belton, 1985 amplia a sua distribuição para todo o centro-sul, concluindo que a ocupação do leste e centro deve ter ocorrido apenas no presente século, visto que estudos anteriores a 1900 não a registraram nestas regiões; não encontrou correlação entre o aumento das áreas de lavouras de arroz e o da área de distribuição do garibáldi. Acredita ser esta a ave atualmente mais abundante no Rio Grande do Sul.

O garibáldi é gregário, podendo ser encontrado em grandes bandos na maior parte do ano. Separa-se em pequenos grupos durante a reprodução, que ocorre em banhados naturais ou nas lavouras de arroz. É acusado, pelos agricultores, de causar danos a esta cultura em todo o ciclo de desenvolvimento.

$\mathrm{Na}$ Argentina, onde existe em grande número, causa grandes prejuízos às lavouras de arroz, segundo Bucher \& Bedano, 1976. Conforme estes autores, a ave sofre combate por parte dos órgãos governamentais, com emprego de redes de captura e fogo nos pouseiros e substratos dos ninhos. Esta ação já refletiu uma diminuição populacional.

No Rio Grande do Sul não são empregados métodos oficiais de controle; os lavoureiros e empregados que cuidam das culturas quebram os ovos ou destróem manualmente os ninhos.

\section{DESCRIÇÃO DA ÁREA DE ESTUDO}

O local de estudo foi uma lavoura de arroz na Vila do Taim, município de Rio Grande $\left(32^{\circ} 34^{\prime}-52^{\circ} 32^{\prime}\right)$, Rio Grande do Sul. Nesta cultura existiam pequenos banhados de vegetação natural, em meio ao arroz. Para o presente estudo foi escolhido um destes banhados, que apresentava 9 ninhos, em diferentes estágios. A vegetação predominante era: $\mathrm{Sa}$ gittaria montevidensis, Echinochloa crusgalli, Axonopus fissifolius, Cynodon dactylon, Paspalum dilatatum, Panicum decipiens, Setaria geniculata, Digitaria cf. sanguinailis, Agrostis montevidensis e Leersia hexandra, dentre outras. O banhado estava cercado de arroz e valos d'água. Apresentava aproximadamente $600 \mathrm{~m}^{2}$ e os ninhos estavam dispostos conforme a fig. 1 .

\section{MÉTODOS DE ESTUDO}

O trabalho de acompanhamento de 9 ninhos fói realizado de 27 de fevereiro ao final do mês de março de 1983. No entanto, vários registros foram feitos nos anos de 1981 a 1983, em locais diversos, usados para dar maior suporte aos dados numéricos e de médias. 


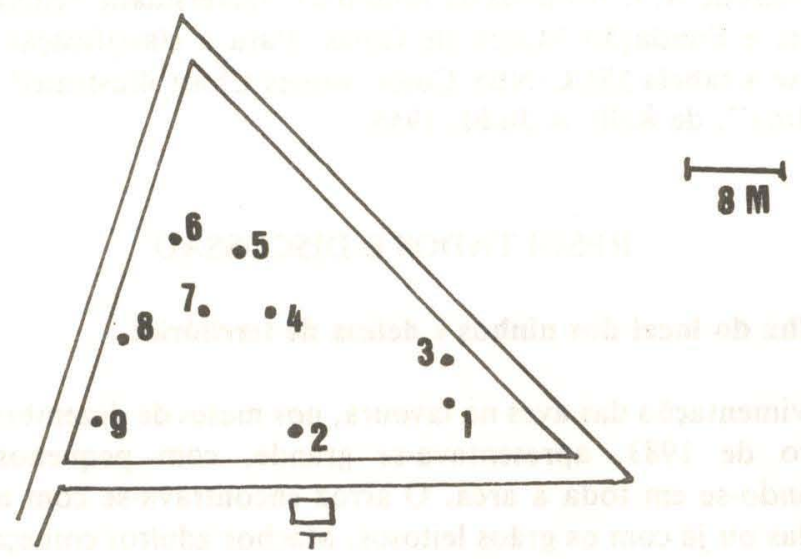

Fig. 1: Esquema da área de estudo, local dos ninhos e da torre de observação (T).

Não foi encontrada concentração de ninhos nos campos de arroz. Estes acham-se muito esparsos. Apenas nestes banhados naturais o número máximo de ninhos foi de 15, em fevereiro de 1982 .

Uma torre de quatro metros de altura, de canos galvanizados desmontáveis, foi colocada à beira da lavoura, para as observações de comportamento efetuadas com binóculo 8x30 e telescópio 10-30x.

Os ninhos foram numerados e marcados com estacas de ferro a $\mathbf{3 0}$ $\mathrm{cm}$ dos mesmos. Medições de ninhos e ovos foram feitas em vários locais; apenas dois ninhos foram medidos no local do estudo. Para tal utilizou-se paquímetro Mitutoyo e trena. Nos ninhos foram considerados diâmetro interno e externo; altura (externamente, da parte superior até a mais inferior) e profundidade (da borda superior até o fundo do ninho, internamente).

Dezesseis indivíduos capturados com redes de neblina foram marcados (10 fêmeas e 6 machos) com anilhas numeradas de alumínio do CEMAVE (Centro de Estudos de Migração de Aves) e plásticas coloridas. Destas aves, apenas 4 pertenciam ao grupo reprodutor em observação.

Para a determinação do conteúdo estomacal, 27 aves foram coletadas em locais diversos na mesma lavoura e 9 após a colheita do arroz. Foi realizada a separação do material com o auxílio de microscópio estereoscópio Olympus. As sementes foram identificadas pelo Instituto de Pesquisas Agronômicas da Secretaria da Agricultura do Estado do Rio Grande do Sul; o material vegetal da área foi determinado pelo Núcleo de Vegetais Inferiores e Superiores do Museu de Ciências Naturais da Fundação Zoobotânica do Rio Grande do Sul.

Peles taxidermizadas do Estado foram comparadas com peles já 
classificadas de $A$. r. frontalis do Museu da Universidade Federal de Belo Horizonte e Fundação Museu de Goiás. Para a classificação de cores utilizou-se a tabela ISCC-NBS Color Names Chart illustrated with centroid colors", de Kelly \& Judd, 1955.

\section{RESULTADOS E-DISCUSSÃO}

\section{Escolha do local dos ninhos e defesa de território:}

A movimentação das aves na lavoura, nos meses de dezembro de 1982 e janeiro de 1983, apresentava-se grande, com pequenos bandos alimentando-se em toda a área. $\mathrm{O}$ arroz encontrava-se com as espigas florescidas ou já com os grãos leitosos. Machos adultos começaram a se concentrar em pequenos banhados naturais no meio do arroz e a defender o território contra outras aves. Para isto ficam bastante conspícuos, pousados em hastes altas na vegetação, distantes uns dos outros cẹrca de 4 metros. Expulsam, através de vozes e posturas, outros machos que se aproximam do local. Cortejam e seguem fêmeas que passam por seus territórios.

O movimento começou a diminuir com o amadurecimento do arroz, no mês de fevereiro, quando foram então vistos apenas pequenos bandos de sexo indeterminado (fêmeas e jovens apresentam plumagem semelhante). Süpõe-se que sejam fêmeas que necessitam se acasalar. Nesta fase inicial do processo, todas as fêmeas cortejadas pelos machos retiravam-se para longe.

A defesa do território é realizada por meio de vozes e posturas agressivas, contra machos da mesma espécie, outras espéciès de aves (tiranídeos, garças, etc.) e, quando acasalado, contra fêmeas de sua espécie.

\section{Construção do ninho e acasalamento:}

Cabe ao macho a construção dos ninhos. No gênero Agelaius é sabido que a fêmea constrói o ninho nas espécies $A$. phoeniceus e $A$. tricolor (bibliografia abundante), $A$. thilius (Orians, 1980) e $A$. xanthomus (Post, 1981). Wiley \& Wiley, 1980, registraram que o macho de $A$. icterocephalus é o responsável pela construção do ninho.

De novembro de 1981 a abril de 1983 foram observados 48 machos construindo ninhos. Duas fêmeas colocaram uma forração interna, após os machos terem construído os ninhos. Klimaitis, 1973 afirma que as fêmeas constroem o ninho nesta espécie, que observou em Buenos Aires. Belton, 1985 também constatou que esta tarefa cabe aos machos.

Para a edificação do ninho os machos utilizaram, no local do estudo, a vegetação aquática ou folhas de arroz. O material preferido foi $S a$ gittaria montevidensis, vegetal abundante na área. Esta planta apresenta 
talos fibrosos e grossos, que aparecem freqüentemente quebrados e espalhados por cima da água. Os machos desfiam as hastes quebradas com o bico, segurando-as com os pés e batendo as asas para manter o equilíbrio. As tiras obtidas desta maneira são levadas até o lugar escolhido e entrelaçadas a diversas hastes do substrato vegetal. Este varia, podendo ser o próprio arroz, Sagittaria montevidensis ou Echinochloa crusgalli. Neste local havia 7 ninhos no arroz, $1 \mathrm{em} S$. montevidensis e $1 \mathrm{em} E$. crusgalli.

O ninho apresenta a forma de uma taça, semelhante ao das demais espécies de Agelaius (Peña, 1979; Post, 1981), sempre sobre a água (Tab. 1). Nas plantações de arroz, sua altura varia de 20 a $60 \mathrm{~cm}$; em juncos de

Tabela 1

Medidas de 5 ninhos com ovos

\begin{tabular}{ccccc} 
Nọ ovos & diâmetro externo & diâmetro interno & altura & profundidade \\
\hline 1 & 10,0 & 6,5 & 12,0 & 10,0 \\
3 & 10,0 & 8,0 & 10,0 & 9,0 \\
3 & 10,0 & 7,0 & 8,0 & 9,0 \\
3 & 12,0 & 6,5 & 11,0 & 8,0 \\
3 & 9,5 & 6,5 & 12,0 & 9,0 \\
\hline \multirow{2}{*}{ Médias } & 10,3 & 6,9 & 10,6 & 9,0
\end{tabular}

banhados naturais varia de 100 a $200 \mathrm{~cm}$. Medidas de ninhos em construção (Tab. 2) mostram que estes são maiores que os prontos, devido ao material molhado ter maior volume.

Tabela 2

\begin{tabular}{cccc}
\multicolumn{3}{c}{ Medidas de 10 ninhos vazios, em construção } & \\
diâmetro externo & diâmetro interno & altura & profundidade \\
\hline 15,0 & 9,0 & 10,0 & 8,0 \\
11,0 & 9,0 & 10,0 & 9,0 \\
12,0 & 10,0 & 13,0 & 10,0 \\
11,0 & 8,0 & 10,0 & 8,0 \\
10,0 & 9,0 & 12,0 & 10,0 \\
11,0 & 8,0 & 12,0 & 10,0 \\
10,0 & 8,0 & 12,0 & 9,0 \\
11,0 & 6,5 & 11,0 & 8,0 \\
10,0 & 6,5 & 12,0 & 9,0 \\
10,0 & 7,0 & 10,0 & 9,0 \\
\hline Médias 11,1 & 8,1 & 11,2 & 9,0
\end{tabular}

A chegada e o estabelecimento da fêmeas no território dos machos parece estar determinada pela finalização do ninho. Em quatro obsèrvações, a formação do par aconteceu após o ninho estar pronto. Belton, 1985 observou uma fêmea pousada próximo do local onde um macho es- 
tava construindo o ninho.

Duas fêmeas foram vistas iniciando a forração do ninho com capins finíssimos (Axonopus fissifolius), que apanhavam à beira dos valos de água das lavouras. Os machos continuaram a defender o território e um deles seguia de perto a companheira todas as vezes que esta saía para buscar o material para o ninho.

O comportamento de exibição sexual foi apresentado apenas pelos machos. Em uma oportunidade, o macho conduziu a fêmea às porções mais baixas da vegetação, voando ao seu redor com as asas abertas e batidas velozmente. O casal ficou desaparecido por instantes, devendo ter ocorrido aí a cópula, que não foi vista em nenhuma ocasião, talvez devido à dificuldade de visualização na vegetação fechada.

\section{Postura, choco, ovos e filhotes:}

Em um caso observado, a postura se iniciou após dois dias de trabalho da fêmea (forração interna do ninho). O número de ovos, em 62 ninhos observados em diversos ambientes, variou de 1 a 4 , sendo 3 o número mais freqüente (em 42 ninhos). Acredita-se que a postura só devia estar concluída nos ninhos que apresentavam mais de 2 ovos, pois apenas nestes as fêmeas iniciavam o choco ou estavam nele.

Os ovos são postos um em cada dia. Sua cor varia e foi classificada com o ISCC-NBS, s/d: em 5 ovos, 1 foi branco-azulado; 2 verdevívido-pálidos; 1 branco-esverdeado e 1 cinza-azulado-claro. No polo maior os ovos apresentam pontos, manchas ou linhas negras ou vermelho-escuras. O peso de 3 ovos foi de $2,9 \mathrm{~g} ; 3,0 \mathrm{~g}$ e $3,2 \mathrm{~g}$ (medidas na Tab. 3).

Tabela 3

Medidas de ovos de $A$. ruficapillus

\begin{tabular}{lll}
\hline 21,9 & $\mathrm{x}$ & 15,5 \\
21,9 & $\mathrm{x}$ & 16,8 \\
22,9 & $\mathrm{x}$ & 16,2 \\
22,9 & $\mathrm{x}$ & 16,4 \\
24,6 & $\mathrm{x}$ & 16,6 \\
25,0 & $\mathrm{x}$ & 18,0 \\
\hline
\end{tabular}

A fêmea realiza os trabalhos de choco. Entre 10 fêmeas anilhadas em 28 de fevereio, 8 apresentavam placa de choco, o que não ocorreu com nenhum dos 6 machos capturados também neste dia.

As fêmeas saem dos ninhos para se alimentar e os machos permanecem em vigília, defendendo território, alimentando-se ou arrumando as penas.

Um macho, ao perceber que a companheira que incubava afastarase do ninho, foi ao seu encontro com as asas abertas, batidas velozmente, quase chocando seu corpo contra o dela. Desta maneira fê-la retornar ao choco. Nero, 1956 também observou um comportamento semelhante nos 
machos de $A$. phoeniceus e cita que Nice, 1943 explica este comportamento como uma resposta instintiva: se a fêmea desaparece, ele começa a cantar; se ela está perto, ele tenta levá-la à situação apropriada (no caso, o choco).

Os machos são monógamos. Foram observados dois cônstruindo um segundo ninho, enquanto as fêmeas estavam chocando. Estes ninhos suplementares estavam 1 e 2 metros do outro. Os machos nesta situação, no entanto, não descuidavam da defesa do território e da companheira. Não foi observada a presença de nenhuma outra fêmea em seus territórios, sendo que todos os intrusos continuaram a ser expulsos por eles. A função deste ninho suplementar não foi descoberta, pois um dos canais teve seu ninho predado e não ocupou o outro, preferindo abandonar a área.

As fêmeas não participam da defesa do território, com exceção de uma que saiu do ninho para auxiliar seu companheiro a expulsar fêmeas de Molothrus bonariensis que, insistentes, não abandonavam as proximidades. No dia seguinte, junto com o primeiro da ninhada, estava um ovo de $M$. bonariensis. A fêmea aceitou o ovo parasita e continuou a postura. Hoy \& Ottow, 1964 também encontraram parasitismo desta ave em A. ruficapillus na Argentina, mas sem sucesso, pois os donos abandonaram os ninhos parasitados.

O período de incubação em dois ninhos com 3 ovos, foi de 13 dias, com a eclosão dos 3 filhotes em cada um deles. O nascimento ocorreu em intervalos de 24 horas. Os filhotes nascem de olhos fechados, sendo que dois deles apresentaram $50 \mathrm{~mm}$ de comprimento total. Possuem, ao nascer, plumas nos tratos capital, humeral, ala, espinhal femural, caudal e crural. Apenas o trato ventral ou axilar apresenta-se nu.

A alimentação dos filhotes é feita principalmente pela fêmea, porém o macho também auxilia na tarefa. Os itens mais comuns levados a eles foram formas adultas de Odonata e larvas de Lepidoptera.

A retirada dos sacos fecais é realizada quando as aves adultas saem do ninho, após terem levado o alimento. Tanto machos como fêmeas foram vistos retirando-os com o bico e levando-os à distância ou simplesmente jogando-os fora.

Quando os filhotes abandonam o ninho permanecem junto com a fêmea, que os alimenta sozinha. Os machos começam a retirar-se da lavoura em pequenos bandos (final de março e começo de abril). Na alimentação dos filhotes que deixaram o ninho, está incluído o arroz, agora completamente maduro. A fêmea descasca os grãos rolando-os transversalmente no bico e desprezando a casca. Os jovens que se alimentam sozinhos preferem Echnochloa e outras gramíneas, talvez por não saberem descascar o arroz.

Os adultos começam a mudar a plumagem e são vistos fora das plantações, alimentando-se de insetos e outros artrópodos, no chão.

Nas lavouras, é época de colheita e a maioria das aves já acabou a 
Tabela 4

Ciclo do arroz em 1983, no local de estudo:

1. Plantio e início do crecimento: outubro e novembro

2. Florescimento das espigas até a formação dos grãos leitosos: dezembro e janeiro

3. Grãos maduros: fevereiro, meados de março

4. Epoca da colheita: março e abril

5. Após a colheita:
Processo reprodutivo da ave

1. Grandes bandos movimentando-se nos banhados e capões próximos às lavouras.

2. Pequenos bandos separados por sexos, alimentando-se no arroz; demarcação de território e início da construção dos ninhos.

3. Poucos indivíduos voando sobre a cultura: pequenos bandos de fêmeas, e alguns machos solitários levando material para o ninho ou alimento para os filhotes. Alimentam-se dispersos, dentró do território.

4. Filhotões já em condições de vôo, sendo alimentados pelas fêmeas, com arroz descascado; bandos pequenos, na maioria de machos, deixam as lavouras em direção aos banhados naturais; alimentam-se de insetos e estâo em muda de plumagem.

5. Grandes bandos mistos e alguns somente de aves pardacentas alimentam-se de grãos de arroz nas restevas.

reprodução. Após a colheita, são vistos novamente grandes bandos de aves, tanto mistos como de indivíduos com plumagem pardacenta. Nove indivíduos deste último tipo de bando foram coletados e todos eram jovens.

\section{Alimentação dos adultos, jovens e recém-nascidos:}

Foram examinados os tratos digestivos de 27 aves coletadas nas lavouras de arroz ou pousadas em capões de Eucaliptus sp. e de 9 jovens que alimentavam-se em restevas.

Os artrópodos ingeridos foram aracnídeos (aranhas) e insetos (Coleoptera, Hemiptera, Odonata, Collembola e Diptera).

Entre as gramíneas, foram ingeridas: Oryza sativa, Echinochloa crusgalli, Paspalum dilatatum, Leersia hexandra.

Os 13 adultos amostrados apresentaram grande diversidade de alimentação, de acordo com a Tabela 5. Apenas duas aves não haviam ingerido arroz, preferindo gramíneas e artrópodos. Nenhuma ave alimentou-se somente de arroz, havendo sempre uma complementação da dieta, com outros vegetais ou artrópodos.

Dos 14 jovens, 6 não ingeriram arroz. A dieta animal esteve presente em 9 indivíduos. 
Tabela 5

Elementos componentes da alimentação de $A$. ruficapillus na zona de estudo

\begin{tabular}{|c|c|c|c|c|c|c|c|}
\hline $\begin{array}{c}\text { Alimento } \\
\text { Aves }\end{array}$ & - Só arroz & $\begin{array}{l}\text { Arroz e } \\
\text { vegetais }\end{array}$ & $\begin{array}{l}\text { Arroz e } \\
\text { invert. }\end{array}$ & Só veg. & Só invert. & $\begin{array}{l}\text { Veg. e } \\
\text { invert. }\end{array}$ & $\begin{array}{c}\text { Todos os } \\
\text { tipos }\end{array}$ \\
\hline Macho adulto & - & - & 1 & - & - & 2 & 4 \\
\hline Fêmea adulta & 1 & 3 & 1 & - & - & 1 & - \\
\hline Macho jovem & 1 & - & 3 & 2 & - & - & 2 \\
\hline Jovem indet. & - & 1 & 1 & 1 & 2 & 1 & - \\
\hline TOTAL & 2 & 4 & 6 & 3 & 2 & 4 & 6 \\
\hline
\end{tabular}

Total de indivíduos: 27

Coletados entre os meses de dezembro e março de 1983, em lavouras de arroz ou capões de Eucaliptos, às suas bordas.

Os 9 jovens coletados após a colheita, nas restevas, apresentaram apenas arroz na moela, e em número mais elevado do que as aves anteriormente coletadas, sugerindo que o arroz caído ao chão é mais fácil de ser ingerido pelas aves.

$\mathrm{Na}$ moela de dois recém-nascidos (um dia de vida) havia 2 e 3 larvas de Lepidoptera.

\section{Predação e abandono dos ninhos:}

Dos nove ninhos que tiveram o estudo iniciado em 27 de fevereiro, 3 foram predados e 4 abandonados pelos donos. Orians, 1961 coloca estes dois fatores como falhas freqüentes do processo reprodutivo, bem como a morte dos ninhegos por inanição ou temperatura muito elevada.

Ninho 1: predado em 11 de março, quando já estava com 3 ovos e a fêmea realizava os trabalhos de choco. Dois ovos desapareceram e o outro foi abandonado.

Ninhö 2: predado em 2 de março, com 1 ovo. As cascas ficaram dentro do ninho e as folhas do suporte, Echinochloa, que o escondiam parcialmente, estavam cortadas e caídas dentro do ninho.

Ninho 9: predado em 28 de fevereiro, com 3 ovos. Medido na véspera. Sobrou apenas 1 ovo, nenhum vestígio dos demais.

Esta predação pode ser atribuída às visitas diárias realizadas para o acompanhamento dos ninhos. Por esta razão, a partir da primeira predação (ninho 9), não foram mais medidos ninhos, ovos ou filhotes. Tentouse utilizar, sempre que possível, caminhos diferentes para evitar a formação de trilhas na vegetação alta. Estes cuidados, no entanto, não impediram a predação de outros dois ninhos. 
O abandono dos ninhos não foi considerado como causado pela presença humana, pois em nenhum momento as aves mostraram-se perturbadas em demasia com o movimento. Afastavam-se dos ninhos com a visita, porém logo retornavam. Utilizavam as marcações colocadas nos ninhos (estacas de ferro), como simples pouseiro ou para a defesa de território.

Dois ninhos (5 e 8) foram abandonados pelos machos quando estavam aparentemente concluídos. Estes não obtiveram a companheira para a continuidde do processo reprodutivo.

Outros dois ( 3 e 7) foram abandonados sem conclusão, sendo que um deles (3) estava sendo construído pelo mesmo macho do ninho 1, que abandonou a área quando este foi predado.

Apenas em dois ninhos deste local (4 e 6) houve conclusão dos trabalhos de choco e eclosão dos filhotes.

\section{Sincronismo entre a reprodução e a cultura de arroz:}

Foi detectado, por três anos consecutivos, um sincronismo entre a reprodução e o ciclo de maturação do arroz. Isto pôde ser comprovado em 1983, quando houve um atraso no plantio do arroz, (iniciou em novembro), devido às fortes chuvas na primavera. Este fato determinou um igual atraso na reprodução, em relação aos anos anteriores.

Como se vê na Tabela 4, o começo do período reprodutivo acontece concomitantemente ao florescimento das espigas de arroz, estando estas em condições de suportar o peso dos ninhos e a uma boa altura da água. Os grãos verdes são sugados pelos adultos; os maduros, descascados, servem de alimento a estes e aos filhotes que abandonam o ninho na época do amadurecimento. Durante a colheita, a maioria das aves já concluiu o processo reprodutivo e os ninhos, de um modo geral, estão abandonados. Nas restevas, grandes bandos de aves aparecem novamente, comendo os grãos de arroz caídos ao chão.

Portanto, desde o início do crescimento, o arroz foi utilizado pelas aves, que nele fizeram seus ninhos e dele se alimentaram em todos os estágios de maturação.

\section{AGRADECIMENTOS}

À Direção do Museu de Ciências Naturais da Fundação Zoobotânica do Rio Grande do Sul, pelo apoio logístico e instalações; ao Núcleo de Vegetais Inferiores e Superiores da mesma Instituição pela determinação dos vegetais; ao Instituto de Pesquisas Agronômicas da Secretaria da Agricultura do Estado, pela determinação das sementes.

À Flávio Silva, pela orientação, sugestões e apoio dado ao trabalho; William Belton, pelas valiosas crítica e sugestões; William Post, pela 
remessa de bibliografia; Enrique Ortiz, pelas informações; José Hidasi, pelas peles de A.r. frontalis; Maria Ignez Ferolla, pelo exame das peles do Museu da Universidade Federal de Minas Gerais.

\section{REFERENCIAS}

Belton, W., 1985. Birds of Rio Grande do Sul, Brazil. Bull. Amer. Mus. Nat. Hist., New York, $180(1)$.

Bucher, E. H. \& Bedano, P. E., 1976. Bird damage problems in Arentina. International studies on sparrows, Poland, 9(1):3-16.

Howard, R. \& Moore, A., 1980. A complete checklist of the birds of the world. London, Oxford Univ. Press. $701 \mathrm{p}$.

Hoy, G. \& Ottow, J., 1964. Biological and oological studies of the molothrine cowbirds of Argentina. Auk, Cambridge, Mass., 81:186-203.

Kelly, K. L. \& Judd, D. B., 1955. The ISCC-NBS method of designating colors and a dictionary of color names, with supplement - ISCC-NBS color-name charts illustrated with centroid colors. Nat. Bur. Stand., Circ. 553. Washington, GPO.

Klimaitis, J. F., 1973. Estudio descriptivo de una colonia de tordos varrilleros (Agelaius ruficapillus). Hornero, Buenos Aires, 11(3): 193:202.

Nero, R. W., 1956. A behavior study of the red-winged blackbird. I. Mating and nesting activities. II. Territoriality. Wilson Bull., Kansas, 68(1):4-37; 68(2):129-150.

Orians,G. H., 1980. Some adaptations of marsh-nesting blackbirds. Monographs in Population Biology, 14. New Jersey, Princeton Univer. Press. 295 p.

Paynter, R.A., 1968. Checklist of Birds of the world, 14. Cambridge, Museum of Comparative Zoology.

Peña, M. R. de la, 1979. Enciclopedia de las aves argentinas. Santa Fé, Argentina. Fasc. 7, $312 \mathrm{p}$.

Pinto. O. M. de O., 1944. Catalogo das aves do Brasil. 2. parte. São Paulo Secretaria da Agricultura, Indústria e Comércio. $700 \mathrm{p}$.

Post, W., 1981. Biology of the yellow-shouldered blackbird - Agelaius on a tropical island. Bull. Florida State Mus. Biol. Sci., Gainesville, 26(3):125-202.

Wiley, R. H. \& Wiley, M. S., 1980. Spacing and timing in the nesting ecology of a tropical blackbird: comparison of populations in different environments. Ecol. Monogr., 50(2):153-78. 